difference between the two forces-in other words the asymmetry of the retarding forces-and the resulting curvature in the path taken therefore depend not only on the 'speed' and the 'spin' given the stone, but also on the ice conditions, just as is observed in practice.

Physical Laboratory,

E. L. Harrington.

University of Saskatchewan,
Saskatoon, Sask., Canada.

\section{Holes produced in Ground by Lightning Flash.}

DURING a thunderstorm of considerable severity which passed over a district near Rothbury, Northumberland, on the afternoon of Tuesday, Aug. 12 last, a flash of lightning apparently struck the ground and produced in it a vertical hole, approximately circular in section, and found on measurement to be $1 \mathrm{ft} .11 \mathrm{in}$. in depth. The hole is tapered, being 6 or 7 in. in diameter at the surface and about 2 in. in diameter at a distance of a foot below the surface. The hole was made in a grass field which lies on sloping ground and which consists of light loamy soil. The field, about 17 acres in extent, is almost surrounded by trees (chiefly firs). The position of the hole is not at the highest part of the field, but several feet below the highest level, while beyond the field are hills and moorland rising to a height of some hundreds of feet above the field. In the field is a clump of fir trees, close to which is a small hut, distant from the hole about 60 yards. A gamekeeper who was in the hut at the time the flash occurred was thrown violently backwards by the concussion which followed the flash, although he is confident he did not experience any electric shock. A hen in a coop about $10 \mathrm{ft}$. from the hole was killed, as also were four young pheasants, one inside the coop, and three near, but outside, it. A heavy rain accompanied the storm, which might account for the absence of any sign of burning round the hole. There were also two smaller holes formed at distances respectively of $4 \mathrm{ft} .6 \mathrm{in}$. and $7 \mathrm{ft} .6 \mathrm{in}$. from the main hole. The first was nearly horizontal, was open on the surface for some 10 in., and, for the few inches where it penetrated the surface, was about half an inch in diameter. The second was smaller still, slightly inclined to the vertical, and approximately a quarter of an inch in diameter and some two or three inches deep.

Apart from the well-known phenomenon of 'fulgurites', it would be interesting to learn if effects similar to those above described are familiar to meteorologists. WiLfRed HaLI.

Hepple, Northumberland, Aug. 26.

\section{Adsorption of Hydrogen and Carbon Monoxide on Oxide Gatalysts.}

IN the course of experiments on the heats of adsorption of hydrogen and carbon monoxide on oxide catalysts, it was observed that these gases behaved in a curious manner on desorption. Hydrogen or carbon monoxide adsorbed at room temperature on the $\mathrm{ZnO}-\mathrm{Cr}_{2} \mathrm{O}_{3}$ eatalysts at equilibrium pressures of $10^{-3}-10^{-4} \mathrm{~cm}$. was evolved on raising the temperature to $100^{\circ}-120^{\circ}$, but within a period of $20-30$ minutes, it was readsorbed on the surface giving a hard vacuum in the containing vessel. On further raising the temperature, no gas was evolved until $350^{\circ}$ C., when water vapour or carbon dioxide respectively was liberated. Mixtures of hydrogen and carbon monoxide behaved similarly, being evolved and readsorbed at $100^{\circ}-120^{\circ} \mathrm{C}$. and finally at $350^{\circ} \mathrm{C}$. being converted into a mixture of water and carbon dioxide, no appreciable quantities of organic compounds being formed.

Hydrogen on copper oxide gives similar phenomena, as was shown by Mr. M. H. Hall.

Hydrogen or carbon monoxide is thus adsorbed on oxide surfaces in two distinct ways, one occurring at room temperatures, the process being reversible, and the other occurring at higher temperatures, which is irreversible. The reduction of oxides by either hydrogen or carbon monoxide therefore occurs in three stages, (1) the physical adsorption of hydrogen, (2) the chemical combination with the surface atoms, and (3) the desorption of water or carbon dioxide. It is curious that the physically-adsorbed gas must leave the surface before it can enter into chemical combination with the metallic oxides.

W. E. Garner.

Department of Physical Chemistry,

F. E. T. KINGMan.

The University, Bristol.

\section{Capture of Electrons by a-Particles.}

Experiments, similar to those of Davis and Barnes (Phys. Rev., 34, 152, 1929; 35, 217, 1930), have been made, in which a beam of $a$-particles passed through a stream of electrons, moving parallel to the $a$-particles. The apparatus differed from that of Davis and Barnes chiefly in that a Geiger counter, with mechanical recording system, was used in place of a scintillation screen, and that the polonium was inside the evacuated vessel. The number of singlycharged particles was always about one per cent of the total. The numbers of both doubly- and singlycharged particles were found to be entirely unaffected by the electron stream throughout the voltage range investigated, namely, from 450 to 750 volts. In particular, no capture was observed when the velocities of $a$-particles and electrons were nearly equal. Capture by the doubly-charged particles to an extent of less than 0.5 per cent would probably not have been detected, on account of probability error. N. A. de Bruyne was associated with me during part of this work.

Cavendish Laboratory,

H. C. WeBster. Cambridge.

Palæolithic Man in North-East Ireland.

THE series of Late Glacial and post-Glacial deposits reported upon by Dr. R. Lloyd Praeger from the Lagan estuary at Belfast ${ }^{1}$ has been described as the most complete stratigraphical record of the post-Glacial sequence in the British Isles. The basal reassorted boulder clay was here overlain by grey sand with cold fauna, an early peat yielding Cervus megaceros, and superimposed estuarine clays, the lower of which has been elsewhere shown to have preceded the deposition of the well-known $25 \mathrm{ft}$. raised beach. We have recently found in such lower estuarine clay, in the neigh. bourhood of Larne, a derived but well-developed Magdalenian industry in flint. This industry will also be described by Mr. Burchell in his presidential address to the Prehistoric Society of East Anglia for 1931.

\section{J. P. T. BURCHELL. \\ C. Blake Whelan.}

1 Praeger, "On the Estuarine Clays at the new Alexandra Dock, Belfast": Proc. Belfast Nat. Field Club, series 2, vol. 2, Appendix for 1886-87, pp. 29-52, 1887 .

No. 3175 , VoL. 126] 